\title{
A SUBJETIVIDADE EM ALFRED SCHUTZ
}

Creusa Capalbo

SÍNTESE - O artigo pretende mostrar de como, na obra de Alfred Schutz, o mundo cotidiano Lebenswelt no sentido da fenomenologia - é expressão do mundo intersubjetivo experenciado pelo ser humano em sua atitude natural, mundo este que se constitui no lugar propriamente dito da sociabilidade e das mudanças sociais. A questão da intersubjetividade - deixada sem solução por Husserl - seria para Schutz, na elaboração de sua sociologia fenomenológica, não um problema a ser resolvido, mas uma categoria ontológica fundamental da existência humana.

PALAVRAS-CHAVE - Subjetividade. Intersubjetividade. Lebenswelt. Sociologia fenomenológica.
ABSTRACT - This article seeks to show how the concept of everyday world (Lebenswelt, in a phenomenological sense) is articulated in Alfred Schutz's corpus in order to express the intersubjective world experienced by human beings in their natural attitude and constituted as the proper locus of sociability and social changes. The question of intersubjectivity - left unanswered by Husserl - remains for Schutz not so much a problem to be solved in the elaboration of his phenomenological sociology, but rather a basic ontological category of human existence.

KEY WORDS - Subjetivity. Intersubjectivity. Lebenswelt. Phenomenological sociology.

\section{Introdução}

Alfred Schutz nasceu em Viena em 13/04/1899. Foi professor de pesquisa em sociologia na Universidade de Viena, além de exercer trabalho em advocacia. Em 1938, devido à ameaça de Hitler de ocupar a Áustria e à perseguição dos judeus, emigrou para Paris e um ano depois para os Estados Unidos. Morreu na cidade de Nova York em 20/05/1959.

Schutz publicou em Viena, em 1932, o seu primeiro livro que buscava dar à sociologia uma base filosófica quanto aos seus fundamentos. Essa obra vem marcada pela discussão e aprofundamento da sociologia compreensiva de $\mathrm{M}$. Weber e na busca de fundamentação desta ciência inspirada na fenomenologia de Husserl. Esta obra intitulou-se $A$ fenomenologia do mundo social ${ }^{1}$ e, conforme observa van Breda, ele buscou a origem das categorias, que são próprias das Ciências Sociais,

\footnotetext{
Professora da UERJ - Universidade Estadual do Rio de Janeiro.

CP. I, p. VII, Prefácio de Van Breda.
} 
na vida da consciência, vinculando, assim, a sociologia compreensiva de Weber com a fenomenologia de Husserl. Ele queria, pois, tratar da "construção significativa da realidade social".

Husserl recebeu um exemplar do livro em alemão de A. Schutz, que este the enviara, e agradeceu dizendo: "Estou ansioso por conhecer um fenomenólogo tão sério e completo, um dos poucos que têm penetrado no núcleo de significação da obra de toda a minha vida, cujo acesso é infelizmente tão difícil, e que promete continuá-la como representação da autêntica philosophia perennis, único futuro possivel para a filosofia".

Nos Estados Unidos teve a oportunidade de entrar em contato com antigos discípulos de Husserl, tais como Darion Cairn, Aron Gurwitsch, Marwin Farber, Felix Kaufman. Junto com M. Farber fundou a Sociedade Internacional de Fenomenologia. Publicou livros em diversas revistas, os quais foram reunidos nos três volumes de Collected Papers.

O propósito central de Schutz foi o de estabelecer os fundamentos de uma sociologia fenomenológica, conforme já dissemos acima. Para ele, o sentido da ação social, objeto principal das ciências sociais, deve voltar-se para a sua fonte originária que reside na vivência intencional da consciência dos sujeitos da ação numa relação interpessoal. Pergunta Schutz: "Como o eu do outro me é dado de forma significativa, tendo em vista a impossibilidade de alguém observar as vivências da outra pessoa da mesma maneira como a própria pessoa o faz? Se eu pudesse estar consciente de toda a experiência do outro, ele e eu seríamos a mesma pessoa". ${ }^{3}$ Para Schutz só podemos apreender as vivências do outro mediante a representação "significativo-simbólica", sendo que o seu corpo ou qualquer artefato cultural por ele produzido, se apresenta como "um campo de expressão dessas vivências".

\section{Ponto de partida para a compreensão da subjetividade}

Do ponto de vista fenomenológico a base de qualquer pesquisa está no mundo da vida, no mundo cotidiano, no mundo pré-reflexivo, também chamado por Husserl de Lebenswelt. Trata-se de descrever, explicitar, alcançar o invariante ou Eidos, compreender e interpretar o mundo cotidiano, pois neste reside a fonte de significados que é essencial e central para toda pesquisa.

Husserl queria encontrar os pressupostos de toda ciência para elucidá-los. Daí o seu ponto de partida ser a experiência da consciência humana que vive e age no mundo da vida que este percebe, interpreta e faz sentido para ela. A consciência intencional, enquanto direção para algo, consciência de alguma coisa, está sempre ligada aos conteúdos da experiência. Tais conteúdos ou "objetos intencionados"

Walsh, G. Introdução in Fenomenologia del mundo social de A. Schutz, Buenos Aires, Paidós, 1973. Texto da correspondência de Husserl, citado na introdução do livro.

4 Schutz, A. Fenomenologia del mundo social, p. 135.

Ibid., p. 130. 
são considerados, após a redução, como unidades de sentido ou de significado no mundo da consciência. Trata-se, pois, de entender a experiência subjetiva e seus atos, dos quais o de atribuir sentido às coisas é o principal para Husserl, pois as coisas nelas mesmas não têm sentido. A questão da subjetividade e da intersubjetividade se coloca para Husserl como fundamental e ele chega a falar, conforme se lê em Helmut R. Wagner, que o "intersubjetivo", fenomenologicamente reduzido e concretamente apreendido, é visto como uma sociedade de pessoas que compartilham uma vida consciente".

Husserl já dissera, antes de Schutz, que a interrogação da filosofia, como ciência universal e fundante, deve remontar aos últimos pressupostos do conhecimento. Ele assim se expressa em seu "Pós-Fácio às suas idéias diretrizes para uma fenomenologia pura": "Esta interrogação conduz inicialmente à vida e aos seres subjetivos e universais que enquanto são pré-científicos já são pressupostos em toda elaboração teórica; e daí - e este é o passo decisivo - a subjetividade transcendental [...] como lugar originário de toda doação de sentido e de toda verificação do ser". ${ }^{6}$ Ser sujeito e reconhecer o outro como outro, estranho a mim, como não-eu sob a forma do "eu do outro", é reconhecê-lo como um ego que tem poder de realizar atos significantes. Mas eu não posso vivenciar "em carne e osso", pela intuição, a vivência do outro, a não ser, como o diz Husserl, pela via da intropatia e da interpretação, supondo a analogia. É graças à analogia que eu compreendo que o outro sujeito é um certo eu, dado, presente, face à minha consciência. $\mathrm{O}$ eu do outro é afirmado por analogia ao meu ego. Para Husserl, a fenomenologia deve examinar a "experiência de si própria do eu" e também a experiência daí derivada, a saber, de "outros eus e da sociedade".

Desenvolver toda esta temática em Husserl seria nos distanciar do tema da nossa comunicação.

$\mathrm{Na}$ verdade, Husserl não teve êxito em desenvolver uma teoria transcendental do outro, de uma subjetividade que é outra distinta da minha, que é codeterminante de sentido.

\section{Alfred Schutz e a subjetividade}

Para Schutz o sujeito social, em sua ação social visando mudanças, requer a compreensão do fundamento da subjetividade, pois o mundo social não está lá fora como um objeto em si com características independentes dos indivíduos que as experimentam. O mundo social é constituído através da comunicação e da ação intersubjetiva dos sujeitos empenhados nesta interação significativa.

A chave mestra para a compreensão da obra de Schutz é a sua intenção de aprofundar a filosofia da realidade mundana, da realidade da vida do sentido comum. O que ele pretende, enquanto filósofo, é fazer deste pressuposto do sentido

5 Wagner, Helmut R. Fenomenologia e relações sociais. Textos escolhidos de A. Schutz, Introdução, p. 4.

Husserl, E., Post Face, p. 373. 
comum da vida social o objeto de sua investigação crítica, obter um fundamento racional da vida cotidiana, examinando as suas múltiplas tipificações.

Para Schutz o mundo do sentido comum, o mundo cotidiano, o Lebenswelt, são expressões do mundo intersubjetivo vivenciado, experimentado pelo homem na atitude natural, como denominava Husserl. $E$ o que lhe interessa sobretudo é mostrar que este mundo do sentido comum é o lugar da ação social, onde se dão as mudanças sociais.

A questão deixada sem solução por Husserl, de como é possível conhecer o outro enquanto um si mesmo no plano transcendental, não desinteressa a Schutz, embora ele dela se distancie na prática. $\mathrm{O}$ enfoque de Schutz sobre a intersubjetividade se centra nas tipificações do mundo do sentido comum, nas dimensões do mundo social enquanto mundo vivido face a face, na relação tu, na percepção presente de um e de outro; ou então enquanto mundo dos contemporâneos, com os quais não estou em relação direta e imediata de face a face, mas numa relação de vivência no tempo e no espaço de nossa situação existencial, ou ainda enquanto mundo dos meus predecessores, em sua forma temporal pretérita, ou mundo dos meus sucessores, em sua forma temporal futura ou por vir.

Para Schutz, bem como o fora para Husserl, a subjetividade do meu eu se distingue dos outros corpos, na esfera da natureza, inicialmente por ser um corpo próprio unido psico-fisicamente. Da mesma forma o meu eu se distingue do eu de outrem, pois este se apresenta a mim, preliminarmente como um corpo psicofísico. Isto se dá graças a uma "transparência aperceptiva" a partir do meu próprio corpo e que Husserl chamava de apercepção analogizante ou apresentação, e que nada mais é do que uma forma particular de intencionalidade imediata. Assim, tanto para Husserl quanto para Schutz, as pessoas se dão à visada da consciência neste mundo da vida que nos é comum, não são dadas como objetos mas sim como sujeitos correlativos, como companheiros; o mundo circundante comunicativo se constitui na experiência do outro, na compreensão recíproca e no acordo, considerando o outro como companheiro. Pode, no entanto, haver outras modalidades não-comunicativas, não recíprocas, egoístas, discordantes, agressivas etc. Para Husserl e Schutz, o fundamento da socialidade está na vida social comunicativa que pode prover o mundo de um significado espiritual. ${ }^{7}$ São subjetividades sociais que atuam no mundo de formas superiores das comunidades espaçotemporais, histórico-culturais de uma das sociedades graças à lei fundamental das motivações humanas. Pode-se dizer, em outras palavras, que não habitamos a natureza, mas sim o mundo circundante já trabalhado pela mão do homem, pelos artefatos, penetrado pela linguagem, ou seja, habitamos o mundo da realidade social diretamente por nós vivenciado. Esse "mundo comum é o solo da nossa existência, ou seja, da subjetividade em suas formas de convivência social. $\mathrm{O}$ sujeito é auto-instituidor de si mesmo no seio das estruturas sociais e culturais da existência inter-humana, intersubjetiva, e não apenas um ser orgânico e psíquico.

7 Husserl, E. Idées, p. 586-614. 
A subjetividade será concebida como uma estrutura humana de totalidade, contendo elementos interdependentes, sendo que o meio pelo qual os homens se comunicam e se entendem é mediado pelo corpo próprio e pela linguagem.

Após longos anos de estudos das teorias de Husserl, Schutz chegou à conclusão de que as inúmeras tentativas de Husserl para resolver a questão do "problema da intersubjetividade" ao nível de uma fenomenologia transcendental haviam fracassado. Ele sugere que a intersubjetividade seja considerada "uma categoria ontológica fundamental da existência humana", ou seja, ela é inquestionável face a toda experiência humana imediata no mundo da vida. Ela não se constitui como um problema a ser resolvido. Ela é algo já dado para o sujeito que vive no mundo da vida, ou seja, a experiência imediata de outros sujeitos surge num ambiente de comunicação comum. Embora sejam vivenciados de pontos de vistas diferentes, levando em consideração as diferentes situações biográficas, esse ambiente nos põe face a objetos e eventos que são percebidos por mim e pelos outros. Cada um vivencia de acordo com a sua própria experiência da situação e vivência o vivenciar da situação por outra pessoa. É o que Schutz chama de experiência "nós" ou "tese geral do álter ego".

$\mathrm{Na}$ atitude do mundo natural o mundo não é o mundo privado do indivíduo, mas sim um mundo comum a todos nós, no qual não temos, neste nível, como diz Schutz, um "interesse teórico, mas sim eminentemente prático". E esse mundo, continua ele, é que temos de modificar através de nossas ações. ${ }^{9}$

Conforme já dissemos no Lebenswelt eu me encontro, em qualquer momento da minha existência, numa dada situação biográfica determinada. E, como escreve Schutz, "a essa situação biográfica determinaḍa pertence não só a minha posição no espaço, tempo e sociedade, mas também a minha experiência de que alguns elementos do meu Lebenswelt me são impostos, enquanto outros estão sob meu controle, ou podem ser postos sob meu controle, sendo, portanto, modificáveis". ${ }^{10}$

Assim como Husserl já o dissera, Schutz igualmente escreve que "o conhecimento da mente do outro indivíduo só é possivel através de eventos que ocorrem ou são produzidos por seu corpo. Na terminologia de Husserl, isto é um caso relevante de referência de apresentação". O corpo do outro sujeito, bem como todos os objetos materiais, são dados a minha percepção original ou estão em presença originária, como prefere dizer Husserl. E Schutz continua: "sua vida psicológica, porém, não me é dada em presença originária, mas somente em co-presença; não é presentada, mas apresentada"."

Segundo Schutz, o ego só pode vivenciar o seu próprio eu de modo pretérito por meio da reflexão, que se volta para o pólo noético da vida intencional da consciência. Já o álter ego é captado de modo presente vivido, a sua subjetividade é

8 C.P. III, p. 82 . Ver ainda Husserl, Cahiers de Royaumont, Philosophien III, E. Husserl - 1859-1959, The Hague, M. Nijhoff, p. 86-98.

Ibid., p. 15-39 
afirmada como sendo "a corrente de pensamento subjetiva que pode ser vivenciada em seu presente vivido [...] e ela é simultânea a nossa própria corrente de consciência, visto que compartilhamos o mesmo presente vivido". ${ }^{12}$

Assim o outro é como eu, capaz de agir e de pensar, de amar e de odiar, de ouvir ou tocar música, posto que a sua consciência, tanto quanto a minha, é intencional e tem a mesma estrutura de tempo. Ela é capaz de realizar experiências de presentificação, de retenções e protensões, de memória e de atenção, situar-se no horizonte do pensamento de agir e querer etc. Vejamos como Schutz fala sobre tal assunto: "na medida em que cada um de nós pode vivenciar os pensamentos e os atos do outro no presente vivido, enquanto que ambos só podemos captar os nossos próprios no passado, por meio da reflexão, [...] esse presente comum a ambos é o campo puro do 'Nós'. [...] Nós participamos [...] sem um ato de reflexão, da simultaneidade vivida do 'Nós', enquanto o Eu só aparece após o retorno do reflexivo". ${ }^{13}$

Para Schutz, estas análises descritivas do mundo da vida em sua cotidianidade, não podem ser impugnadas pela fenomenologia transcendental. O outro nos é dado numa experiência genuína e imediata no plano mundano. O conhecimento do senso comum da vida cotidiana e o fundo não questionado, mas sempre questionável, a partir do qual os conceitos científicos e filosóficos se originam. Assim o Lebenswelt é a matriz de emergência de conhecimentos reflexivos. Esse conhecimento em primeiro nível do mundo da vida se refere ao significado subjetivo que uma ação tem para 0 ator. As Ciências Sociais, diz Schutz, não podem deixar de incluir este significado subjetivo em seus constructos de segundo grau, sendo estes contructos objetivos típicos, idealizados, "sistemas teóricos contendo hipóteses gerais verificáveis". Mas, insiste Schutz, estas idealizações das Ciências Sociais não podem deixar de lado que eles se reportam "as motivações humanas, dos fins e meios humanos, do planejamento humano, em suma, das categorias da ação humana". ${ }^{4}$

\title{
3 A ação no mundo da vida é uma atividade subjetiva
}

Para Schutz, ação é uma atividade voltada para um projeto, voltada para um futuro, dirigida intencionalmente para algo. Assim o cientista social "não deve procurar o sentido da ação fora do ator que ele está observando no mundo social, mas sim procurar o sentido que este ator atribui a sua atuação no mundo social. $O$ significado de um ato do sujeito é um ato de atribuição de sentido por parte do próprio sujeito, e é sempre significado de intenção subjetiva". ${ }^{15}$

\author{
Ibid. \\ Ibid. \\ Ibid. \\ Schutz, Alfred, Estudios sobre teoria social, p. 20-69.
}


Segundo Schutz, devemos distinguir ação e ato. A ação ocorre no tempo e é compreendida pela consciência temporal como uma realização imanente à duração na consciência. O ato é o que já foi realizado e transcende a duração. ${ }^{16}$

As experiências espontâneas com significado subjetivo são condutas subjetivas para Schutz. E toda conduta baseada num projeto previsto pelo sujeito é uma ação. É pela intenção que um projeto previsto se transforma num objetivo e num propósito. Schutz se detém nas análises da ação e do ato em relação aos modos de temporalização em que eles se dão, bem como na questão da motivação da ação, da ação racional, da antecipação e do projeto, da previsão, todos temas interligados à ação e ao ato. Nós não temos tempo para desenvolver todos os itens acima mencionados, nem tão pouco, tempo para ver como Schutz se apropria e às vezes inova em relação a tais temas tratados por Husserl em Idéias III.

\section{Tipificação e subjetividade}

Para mostrar que a pesquisa social da subjetividade não se refere ao indivíduo único em sua singularidade, Schutz terá que recorrer ao conceito de tipificação a partir da sociologia compreensiva de Weber. Com efeito lemos o que se segue na obra de Schutz: "Na maior parte do tempo meus encontros com os outros, na vida cotidiana, são típicos em duplo sentido: apreendo o outro como um tipo e interatuo com ele numa situação que é por si mesma típica [...] O que se experimenta na percepção do objeto é transferido aperceptivamente a qualquer outro objeto similar que é percebido como simplesmente do mesmo tipo [...] Da mesma forma a apreensão do outro sujeito se dá por transferência aperceptiva por meio de esquemas tipificadores". ${ }^{17}$

Vê-se pois, que não só de objetos que se tem uma percepção típica, mas também dos sujeitos, mesmo quando estamos numa relação de interação face a face. Schutz detém-se longamente na explicação deste termo, o que não podemos aqui fazer. No entanto, o que é importante salientar é que a pesquisa social da subjetividade não é do indivíduo único, mas sim o que se constitui como característica típica de um dado corpo social.

A relação social face a face é uma relação direta e estabelece uma relação típica de comunidade, na qual os sujeitos estão voltados um para o outro compartilhando a mesma situação de espaço e tempo social. Já vimos que Schutz chama a esta relação consciente do outro ser humano como pessoa, de relação tu. Ela pode ser unilateral, ou seja, quando só um se volta para a presença do outro. Ela pode ser recíproca, quando ambos estão conscientes e voltados mutuamente um para 0 outro, e é então que Schutz a denomina de relação "Nós". Nesta relação, há participação de um na vida do outro, há uma abertura recíproca aos atos intencionais do outro, vivenciamos os conteúdos subjetivos de significados um do outro.

16 Schutz, Alfred, Fenomenologia del mundo social, p. 69.
17 Schutz, Alfred, El problema de la realidad social, p. 39. 
A relação social de meus contemporâneos, que coexistem comigo no tempo, não posso deles ter uma vivência de forma imediata. O conhecimento que posso ter deles é sempre mediato, indireto e impessoal. Posso, no entanto, fazer inferências a partir das evidências diretas das vivências típicas que devem ter. (Por exemplo, um carteiro, o pequeno jornaleiro que entrega o jornal em minha casa etc.). ${ }^{18}$ Para Schutz esta é a relação típica de "orientação eles" cujos atos intencionais são apreendidos como de pessoas anônimas. Essas vivências das pessoas anônimas são conscientes, típicas de alguém, e por isto mesmo podem ser compreendidas com homogêneas e repetíveis. Assim, as tipificações vão-se tomando progressivamente anônimas à medida que se afastam da sua origem fundante que reside na situação face a face.

Schutz observa que o contemporâneo, em sua unidade, se constitui na minha "corrente de consciência, integrada por uma síntese de reconhecimento na qual reúno, monoteticamente, as minhas vivências conscientes de alguém, de uma pessoa distante ou de um grupo de pessoas, sendo pois de pessoas definidas ou anônimas". ${ }^{19}$ Assim, a síntese de reconhecimento é uma representação típica da pessoa, homogênea e repetivel, deixando de lado suas características individuais. Por isto o "tipo" não corresponde a nenhuma pessoa particular, pois, como explica Schutz, "na síntese tipificante do reconhecimento realizo um ato de vivência da corrente da consciência, e portanto, a faço impessoal". ${ }^{20}$ Assim, o "tipo pessoal" nada mais é que uma idealização, um esquema interpretativo do mundo social, fazendo ponte da nossa bagagem de conhecimentos acerca do mundo, tendo um valor de significação do qual nós fazemos uso nas relações interpessoais.

\section{Conclusão}

Vimos que para Schutz a questão da subjetividade está vinculada à da intersubjetividade e que, distanciando-se da temática da fenomenologia transcendental de E. Husserl, a intersubjetividade não é um problema a ser resolvido. Ela é, como ele mesmo diz, "uma categoria ontológica fundamental da existência humana", ela é um pressuposto já dado de toda experiência humana imediata no mundo da vida.

O conhecimento da mente do outro sujeito não é imediato mas mediato, requerendo a atividade corpórea do sujeito que produz eventos e se expressa. 0 outro se mostra a mim apresentando-se pelo seu corpo e é dado à minha percepção como presença originária de seu corpo próprio expressivo. Mas, a sua vida "interior", ou seja, a sua vida psicológica não me é dada como presença originária, pois, como diz Schutz: "se eu pudesse estar consciente de toda a experiência do outro, ele e eu seríamos a mesma pessoa". Por isso, a vivência do outro em sua 
dimensão pessoal da sua vida psicológica, me é dada no todo da pessoa como "co-presença", ou seja, ela não é presença originária mas apresentação.

\section{Referências bibliográficas}

SCHUTZ, Alfred. Der sinnhafte Aufbau der sozialen Welt. Viena, Springer, 1962. Traducao inglesa: The Phenomenology of the social world. Evanston, Ilinois, Northwestern University Press, 1967.

Collected Papers I: The problem of social reality. The Hague, M. Nijhoff, 1962. Abreviado na citação: CP I.

Collected Papers II: Studies in social theory. The Hague, M. Nijhoff, 1964. Abreviado na citação: CP. II Collected Papers III: Studies in phenomenological philosophy. Organizado por Ilse Schutz. The Hague, M. Nijhoff, 1966. Abreviado na citação: CP III

SCHUTZ, A. El problema de la realidad. Buenos Aires, Ed. Amorrortu, 1974.

- A Fenomenologia del mundo social: introducción a la sociología compreensiva. Buenos Aires, Ed. Paidós, 1972.

Estudios sobre teoria social. Buenos Aires, Ed. Amorrortu, 1974.

WAGNER, Helmut R. (org.). Fenomenologia e relaçöes sociais. Textos escolhidos de Alfred Schutz. Rio de Janeiro: Ed. Zahar, 1979. Tradução da edição inglesa de 1970, publicada em Chicago, The University of Chicago Press.

HUSSERL, E. Post-Face a mes idées directrices pour une phénomenologie pure. In: Revue de métaphysique et morale, nov., 1957. Original foi publicado em 1930 in Jahrbuch für Philosophie und phänomenologische Forschung (tomo XI) sob o título Nachwort zu meinen Ideen zu einer reinen Phänomenologie.

—. Idées, vol. II, Paris, PUF, 1967.

- Cahiers de Royaumont, Paris, Ed. Minuit, 1959.

Edmund Husserl: 1859-1959. The Hague, M. Nijhoff, 1959.

CAPALBO, Creusa. Metodologia das ciências sociais: a fenomenologia de Alfred Schutz. 2. ed., Londrina, Editora da Universidade Estadual de Londrina, 1998.

GURWITSCH, Aron. The field of consciousness. Pittsburgh, Duquesne University Press, 1964.

NATASON, M. (org.). Phenomenology and social reality. Essays in memory of Alfred Schutz. The Hague, M. Nijhoff, 1970. 